\title{
Sistem Pakar Pemilihan Obat Secara Swamedikasi Menggunakan Teorema Bayes
}

\section{Expert System Drug Selection on Self-Medication Using Bayes Theorem}

\author{
Raphael Yanarto Septiaji ${ }^{1}$, Ozzi Suria ${ }^{2}$ \\ ${ }^{1,2}$ Fakultas Teknologi Informasi, Universitas Mercu Buana Yogyakarta \\ Jl. Wates Km. 10 Yogyakarta, 55753, Indonesia \\ Email: raphaelaji69@gmail.com ${ }^{1}$, ozzisuria@mercubuana-yogya.ac.id ${ }^{2}$
}

\begin{abstract}
ABSTRAK
Dalam kehidupan sehari-hari, sering kali kita mengalami gejala penyakit ringan seperti pusing, nyeri, demam, batuk, pilek, diare, maag, dan lain lain. Untuk menangani gejala tersebut, biasanya kita membeli obat secara mandiri sebelum memeriksakan diri ke dokter. Istilah ini dikenal sebagai swamedikasi.

Pada penelitian ini akan dirancang sebuah sistem pakar untuk pemilihan obat secara swamedikasi menggunakan teorema bayes. Sistem ini akan memberikan informasi mengenai obat-obatan dalam kategori pengobatan mandiri atau swamedikasi.

Berdasarkan 20 data kasus yang telah divalidasi oleh pakar dan diujikan terhadap sistem, diperoleh tingkat kesesuaian sistem menggunakan teorema bayes pada pemilihan obat secara swamedikasi yang telah diuji adalah sebesar $90 \%$. Hasil keluaran pada sistem hanya dapat menampilkan informasi 1 jenis obat saja.
\end{abstract}

Kata kunci: Sistem Pakar, Obat, Swamedikasi, Teorema Bayes

\begin{abstract}
In everyday life, we often experience symptoms of minor illness such as dizziness, pain, fever, cough, runny nose, diarrhea, ulcer, and others. To deal with these symptoms, usually we buy the drug independently before going to the doctor. This term is known as self-medication.

In this study will be designed an expert system drug selection on self-medication using bayes theorem. This system will provide information about drugs in the category of self-medication.

Based on 20 case data that have been validated by experts and tested on the system, the system accuracy level using bayes theorem in self-medication drug selection which has been tested is $90 \%$. The system will display information of 1 drug type only.
\end{abstract}

\section{Keywords: Expert Systems, Drug, Self Medication, Bayes Theorem}

\section{PENDAHULUAN}

Seiring dengan kemajuan teknologi dan perubahan pola hidup masyarakat yang cenderung kurang memperhatikan kesehatan, maka berkembangnya penyakit di masyarakat tidak dapat dielakkan lagi. Berkembangnya penyakit ini mendorong masyarakat untuk mencari alternatif pengobatan yang efektif secara terapi, tetapi juga efisien dalam hal biaya. Berkenaan dengan hal tersebut, swamedikasi menjadi alternatif yang diambil oleh masyarakat.

Swamedikasi merupakan proses pengobatan yang dilakukan sendiri oleh seseorang mulai dari pengenalan keluhan atau gejalanya sampai pada pemilihan serta penggunaan obat, dan obat yang dapat digunakan untuk swamedikasi adalah obatobatan yang dapat dibeli tanpa menggunakan resep dokter termasuk obat herbal atau tradisional (Rikomah, 2016). Pada pelaksanaannya swamedikasi dapat menjadi sumber terjadinya kesalahan pengobatan (medication error) karena keterbatasan pengetahuan masyarakat akan obat dan penggunaannya. Melihat permasalahan tersebut, peneliti melakukan penelitian dengan judul "Sistem Pakar Pemilihan Obat Secara Swamedikasi Menggunakan Teorema Bayes". Diharapkan dari penelitian ini dapat membantu masyarakat dalam melakukan swamedikasi secara tepat, sehingga terhindar dari kesalahan pengobatan.

\section{TINJAUAN PUSTAKA DAN TEORI}




\subsection{Tinjauan Pustaka}

Sistem pakar digunakan untuk membatu penderita hipertensi dalam memilih obat antihipertensi sesuai dengan kondisi pasien penderita hipertensi dengan meminimalkan resiko yang merugikan bagi pasien. Proses uji validitas pada penelitian ini dalam bentuk matriks konfusi yang bertujuan untuk mengetahui total kinerja sistem. Aturan dari sistem pakar $100 \%$ diujikan dan dicocokkan hasilnya dengan aturan dari pakar sehingga menghasilkan nilai dengan tingkat akurasi sebesar 100\% (Nurhayati, Kusumadewi, \& Miladiyah, 2016).

Sistem pakar dalam bidang kesehatan salah satunya untuk melakukan penentuan jenis obat bagi penderita suatu penyakit. Dengan nilai pengujian berupa nilai persentase dari hasil perhitungan berdasarkan rumus Certainty Factor yang menghasilkan nilai persentase akurasi sebesar 98\% (Fahlefiana, 2013).

Dengan menggunakan aplikasi berbasis mobile yang mudah didapatkan pada saat ini. Kucing sebagai hewan periharaan yang digemarin oleh masyarakat Indonesia namun tidak diimbangi dengan tersedianya dokter hewan yang mencukupi. Data yang diperoleh dari studi literature dari para ahli selanjutnya akan menentukan data penyakit dan data gejala penyakit. Dalam tahap ini, terdapat dua langkah yang dilakukan yaitu proses data identifikasi penyakit dan proses data indentifikasi gejala gejala yang menghasilkan nilai probabilitas sebesar 90\% (Harijanto \& Latif, 2016).

Aplikasi sistem pakar selain digunakan untuk diagnosa penyakit pada manusia, dapat juga digunakan untuk diagnosa penyakit pada tanaman, dalam penelitiannya penerapan sistem pakar diagnosa penyakit tanaman kelapa sawit digunakan untuk membantu para petani kelapa sawit, dalam diagnosa penyakit dan solusi pengobatan tanaman kelapa sawit. Karena di Indonesia salah satu komoditas unggulan dalam bidang perkebunan. Hasil dari pengujian sistem ini mencapai keakuratan sebesar 92,25 \% (Sidauruk \& Pujianto, 2017).

Sistem pakar dalam bidang pertanian dapat membantu para petani dalam mengatasi permasalahan pada tanaman mereka berdasarkan gejala- gejala yang terjadi pada tanaman tersebut sehingga para petani tersebut dapat dengan cepat mencari solusi yang tepat. Tahapan pengumpulan data pada penilitian ini menggunakan studi literatur dan wawancara kepada seorang ahli atau pakar, dan logika metode teorema bayes pada sesi konsultasi sistem, pengguna konsultasi diberi pilihan jawaban yang masing- masing memiliki bobot. Hasil dari penelitian ini menghasilkan nilai keakuratan sebesar $60.85 \%$ (Barus, Mesran, Suginam, \& Karim, 2017)

\subsection{Landasan Teori}

\subsubsection{Obat}

Obat adalah bahan atau panduan bahanbahan yang siap digunakan untuk mempengaruhi atau menyelidiki sistem fisiologi atau keadaan patologi dalam rangka penetapan diagnosis, pencegahan, penyembuhan, pemulihan, peningkatan kesehatan dan kontrasepsi (Departemen Kesehatan RI, 2006).

Obat jadi adalah obat yang sudah dalam bentuk siap pakai, dibedakan antara obat generic dan obat merek dagang. Obat generic adalah obat jadi terdaftar yang menggunakan nama generic yaitu nama obat internasional atau nama lazim yang sering dipakai. Penulisan obat generic menunjukkan 1) Nama generik lebih informatif dari pada nama dagang, 2) Memberi kemudahan pemilihan produk, 3) Produk obat generik pada dasarnya lebih murah daripada produk nama dagang, 4. Resep/order dengan nama generik mempermudah substitusi produk yang sesuai.

\subsubsection{Swamedikasi}

Swamedikasi berarti mengobati segala keluhan pada diri sendiri dengan obat-obat sederhana yang dibeli bebas di apotik atau toko obat, atas inisiatif sendiri tanpa nasihat dokter (Tan \& Rahardja, 2010).

Sedangkan konsep modern swamedikasi adalah upaya pencegahan terhadap penyakit, dengan tentunya mengkonsumsi vitamin dan food suplement untuk meningkatkan daya tahan tubuh.

Kriteria obat yang digunakan dalam swamedikasi sesuai permenkes No.919/MENKES/PER/X/1993: 1) Tidak dikontraindikasikan untuk penggunaan pada wanita hamil, anak di bawah usia 2 tahun dan orang tua di atas 65 tahun, 2) Tidak memberikan risiko pada kelanjutan penyakit, 3) Penggunaannya tidak memerlukan cara atau alat khusus yang harus dilakukan oleh tenaga kesehatan, 4) Memiliki rasio khasiat keamanan yang dapat dipertanggungjawabkan untuk pengobatan sendiri. 


\subsubsection{Sistem Pakar}

Menurut Turban (1995), konsep dasar sistem pakar mengandung keahlian (expertise), pakar (expert), pengalihan keahlian (transfering expertise), inferensi (inferencing), aturan (rules) dan kemampuan menjelaskan (explanation capability). Keahlian (expertise) adalah suatu kelebihan penguasaan pengetahuan di bidang tertentu yang diperoleh dari pelatihan, membaca atau pengalaman. Pengetahuan tersebut memungkinkan para ahli untuk dapat mengambil keputusan lebih cepat dan lebih baik daripada seseorang yang bukan ahli.

\subsubsection{Teorema Bayes}

Teorema bayes merupakan kaidah yang memperbaiki atau merevisi suatu probabilitas dengan cara memanfaatkan informasi tambahan. Dari probabilitas awal yang belum diperbaiki yang dirumuskan berdasarkan informasi yang tersedia saat ini, kemudian dibentuklah probabilitas berikutnya. Probabilitas bayes adalah salah satu cara untuk mengatasi ketidakpastian data dengan formula bayes (Rosnelly, 2012). Yang dinyatakan dalam Persamaan 1.

$$
\mathrm{P}(\mathrm{Hi} \mid \mathrm{E})=\frac{\mathrm{P}(\mathrm{E} \mid \mathrm{Hi}) \mathrm{P}(\mathrm{Hi})}{\sum_{k=l}^{n} \mathrm{P}(\mathrm{E} \mid \mathrm{Hk}) \mathrm{P}(\mathrm{Hk})}
$$

Dimana:

$\mathrm{P}(\mathrm{Hi} \mid \mathrm{E})=$ Probabilitas hipotesa Hi terjadi jika evidence E terjadi.

$\mathrm{P}(\mathrm{E} \mid \mathrm{Hi})=$ Probabilitas munculnya evidence $\mathrm{E}$ jika diketahui hipotesa $\mathrm{Hk}$ benar.

$\mathrm{P}(\mathrm{Hi})=$ Probabilitas hipotesa $\mathrm{Hk}$, tanpa memandang evidence apapun.

$\mathrm{n}=$ Jumlah hipotesa yang mungkin.

\section{METODOLOGI}

\subsection{Alur Penelitian}

Alur penelitian pada penilitian ini dijelaskan dalam bentuk blok diagram dapat dilihat pada Gambar 1.

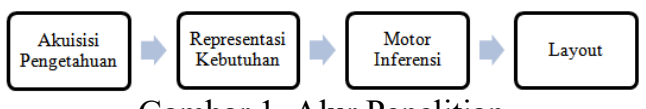

Gambar 1. Alur Penelitian

\subsection{Perancangan Basis Pengetahuan}

\subsubsection{Data Obat}

Tabel data obat dapat dilihat pada Tabel

\begin{tabular}{|l|l|}
\hline \multicolumn{1}{|c|}{ Kode Obat } & \multicolumn{1}{c|}{ Nama Obat } \\
\hline OB001 & Gliseril Guaiakolat \\
\hline OB002 & Difenhidramin HCI \\
\hline OB003 & Dekstrometorfan HBr \\
\hline OB004 & Alpara \\
\hline OB005 & Paracetamol \\
\hline OB006 & Antasida \\
\hline OB007 & Pirantel Pamoat \\
\hline OB008 & Mebendazol \\
\hline OB009 & Piperazin \\
\hline OB010 & Oralit \\
\hline OB011 & Salicyl Talk \\
\hline OB012 & Mikonazol 2\% \\
\hline OB013 & Perak Sulfadiazin \\
\hline OB014 & Povidon Iodine \\
\hline
\end{tabular}

\subsubsection{Data Gejala}

Tabel 2.

Tabel data gejala dapat dilihat pada

Tabel 2. Data Gejala

\begin{tabular}{|c|c|c|}
\hline $\begin{array}{c}\text { Kode } \\
\text { Gejala }\end{array}$ & Nama Gejala & Bobot \\
\hline G001 & $\begin{array}{l}\text { Pengeluaran udara dari } \\
\text { saluran pernapasan secara } \\
\text { kuat, yang mungkin disertai } \\
\text { dengan pengeluaran dahak. }\end{array}$ & 0.8 \\
\hline G002 & Tenggorokan sakit dan gatal & 0.6 \\
\hline G003 & $\begin{array}{l}\text { Pengeluaran udara dari } \\
\text { saluran pernapasan secara } \\
\text { kuat. }\end{array}$ & 0.9 \\
\hline G004 & $\begin{array}{l}\text { Alergi yang disebabkan } \\
\text { oleh debu, serbuk bunga, } \\
\text { cuaca dingin dan bulu } \\
\text { hewan. }\end{array}$ & 0.9 \\
\hline G005 & $\begin{array}{l}\text { Demam, sakit kepala, dan } \\
\text { nyeri otot }\end{array}$ & 0.2 \\
\hline G006 & Mata berair & 0.1 \\
\hline G007 & $\begin{array}{l}\text { Batuk, bersin dan hidung } \\
\text { berair }\end{array}$ & 0.8 \\
\hline G008 & Sakit tenggorokan & 0.1 \\
\hline G009 & $\begin{array}{l}\text { Kepala, leher, dan tubuh } \\
\text { terasa panas, sedang tangan } \\
\text { dan kaki dingin }\end{array}$ & 0.8 \\
\hline G010 & $\begin{array}{l}\text { Mungkin merasa } \\
\text { kedinginan dan menggigil } \\
\text { bila suhu meningkat dengan } \\
\text { cepat. }\end{array}$ & 0.9 \\
\hline G011 & $\begin{array}{l}\text { Nyeri serta rasa panas pada } \\
\text { ulu hati dan dada. }\end{array}$ & 0.8 \\
\hline G012 & $\begin{array}{l}\text { Mual, kadang disertai } \\
\text { muntah dan perut kembung. }\end{array}$ & 0.6 \\
\hline G013 & $\begin{array}{l}\text { Mengeluarkan cacing pada } \\
\text { saat buang air besar atau } \\
\text { muntah. }\end{array}$ & 0.8 \\
\hline G014 & $\begin{array}{l}\text { Badan kurus dan perut } \\
\text { buncit. }\end{array}$ & 0.6 \\
\hline
\end{tabular}

Tabel 1. Data Obat 


\begin{tabular}{|c|c|c|}
\hline $\begin{array}{l}\text { Kode } \\
\text { Gejala }\end{array}$ & Nama Gejala & Bobot \\
\hline G015 & $\begin{array}{l}\text { Kehilangan nafsu makan, } \\
\text { lemas, pusing nyeri kepala, } \\
\text { gelisah dan sukar tidur. }\end{array}$ & 0.5 \\
\hline G016 & $\begin{array}{l}\text { Gatal-gatal disekitar dubur } \\
\text { terutama malam hari. }\end{array}$ & 0.5 \\
\hline G017 & $\begin{array}{l}\text { Gangguan lambung, kejang } \\
\text { perut diselingi diare, } \\
\text { kehilangan berat badan, dan } \\
\text { demam. }\end{array}$ & 0.6 \\
\hline G018 & $\begin{array}{l}\text { Gangguan saluran cerna } \\
\text { (mual, muntah, diare, dan } \\
\text { nyeri ulu hati). }\end{array}$ & 0.7 \\
\hline G019 & $\begin{array}{l}\text { Pusing nyeri kepala, lemah, } \\
\text { dan lelah. }\end{array}$ & 0.4 \\
\hline G020 & $\begin{array}{l}\text { Frekuensi buang air besar, } \\
\text { melebihi normal. }\end{array}$ & 0.9 \\
\hline G021 & Kotoran encer atau cair. & 0.8 \\
\hline G022 & Sakit atau kejang perut. & 0.7 \\
\hline G023 & Demam dan muntah. & 0.5 \\
\hline G024 & $\begin{array}{l}\text { Bintil-bintil kemerahan } \\
\text { pada kulit, terutama pada } \\
\text { daerah-daerah lipatan } \\
\text { tubuh. }\end{array}$ & 0.9 \\
\hline G025 & $\begin{array}{l}\text { Kulit berwarna kemerahan } \\
\text { pada saat lembab. }\end{array}$ & 0.7 \\
\hline G026 & Gatal. & 0.8 \\
\hline G027 & $\begin{array}{l}\text { Lesi berbentuk bulat dengan } \\
\text { pinggir meninggi dan } \\
\text { bersisik, bagian tengah agak } \\
\text { cekung dan sering bebas } \\
\text { dari peradangan. }\end{array}$ & 0.9 \\
\hline G028 & $\begin{array}{l}\text { Sangat gatal, terutama saat } \\
\text { berkeringat. }\end{array}$ & 0.8 \\
\hline G029 & $\begin{array}{l}\text { Peradangan kulit, biasanya } \\
\text { akibat garukan. }\end{array}$ & 0.7 \\
\hline G030 & $\begin{array}{l}\text { Kulit berwarna kemerahan, } \\
\text { melepuh dan terkelupas. }\end{array}$ & 0.9 \\
\hline G031 & Bengkak pada kulit. & 0.8 \\
\hline G032 & $\begin{array}{l}\text { Muncul rasa sakit dan panas } \\
\text { pada kulit. }\end{array}$ & 0.7 \\
\hline G033 & $\begin{array}{l}\text { Sobekan pada kulit yang } \\
\text { mungkin membuat cedera } \\
\text { jaringan kulit di bawahnya. }\end{array}$ & 0.8 \\
\hline G034 & $\begin{array}{l}\text { Pendarahan yang sedikit } \\
\text { sampai sedang yang akan } \\
\text { berhenti sendiri. }\end{array}$ & 0.9 \\
\hline G035 & Sakit atau nyeri & 0.7 \\
\hline G036 & $\begin{array}{l}\text { Luka atau koreng, yang } \\
\text { disebabkan garukan. }\end{array}$ & 0.6 \\
\hline
\end{tabular}

\subsubsection{Data Penyakit} Tabel 3 .

Tabel data penyakit dapat dilihat pada

Tabel 3. Data Penyakit

\begin{tabular}{|l|l|}
\hline Kode Penyakit & \multicolumn{1}{|c|}{ Nama Penyakit } \\
\hline P001 & Batuk berdahak \\
\hline P002 & Batuk alergi \\
\hline P003 & Batuk kering \\
\hline
\end{tabular}

\begin{tabular}{|l|l|}
\hline Kode Penyakit & \multicolumn{1}{|c|}{ Nama Penyakit } \\
\hline P004 & Flu \\
\hline P005 & Demam \\
\hline P006 & Maag \\
\hline P007 & Cacing Kremi \\
\hline P008 & Cacing Gelang \\
\hline P009 & Cacing Tambang \\
\hline P010 & Diare \\
\hline P011 & Biang keringat \\
\hline P012 & Kadas / kurap \\
\hline P013 & Luka bakar ringan \\
\hline
\end{tabular}

\subsubsection{Data Aturan Pakar}

Tabel data aturan pakar dapat dilihat pada Tabel 4.

Tabel 4. Aturan Pakar

\begin{tabular}{|c|c|c|}
\hline Kode Obat & Kode Gejala & Bobot \\
\hline \multirow[t]{2}{*}{ OB001 } & G001 & 0.8 \\
\hline & G002 & 0.6 \\
\hline \multirow[t]{3}{*}{ OB002 } & G001 & 0.8 \\
\hline & G002 & 0.6 \\
\hline & G004 & 0.9 \\
\hline \multirow[t]{2}{*}{ OB003 } & G003 & 0.9 \\
\hline & G002 & 0.6 \\
\hline \multirow[t]{4}{*}{ OB004 } & G005 & 0.2 \\
\hline & G006 & 0.1 \\
\hline & G007 & 0.8 \\
\hline & G008 & 0.1 \\
\hline \multirow[t]{2}{*}{ OB005 } & G009 & 0.8 \\
\hline & G010 & 0.9 \\
\hline \multirow[t]{2}{*}{ OB006 } & G011 & 0.8 \\
\hline & G012 & 0.9 \\
\hline \multirow[t]{4}{*}{ OB007 } & G013 & 0.8 \\
\hline & G014 & 0.6 \\
\hline & G015 & 0.5 \\
\hline & G016 & 0.5 \\
\hline \multirow[t]{4}{*}{ OB008 } & G013 & 0.8 \\
\hline & G014 & 0.6 \\
\hline & G015 & 0.5 \\
\hline & G017 & 0.6 \\
\hline \multirow[t]{4}{*}{ OB009 } & G013 & 0.8 \\
\hline & G014 & 0.6 \\
\hline & G015 & 0.5 \\
\hline & G018 & 0.5 \\
\hline \multirow[t]{4}{*}{ OB010 } & G020 & 0.9 \\
\hline & G021 & 0.8 \\
\hline & G022 & 0.7 \\
\hline & G023 & 0.5 \\
\hline \multirow[t]{3}{*}{ OB011 } & G024 & 0.9 \\
\hline & G025 & 0.7 \\
\hline & G026 & 0.8 \\
\hline \multirow[t]{3}{*}{ OB012 } & G027 & 0.9 \\
\hline & G028 & 0.8 \\
\hline & G029 & 0.7 \\
\hline \multirow[t]{3}{*}{ OB013 } & G030 & 0.9 \\
\hline & G031 & 0.8 \\
\hline & G032 & 0.7 \\
\hline \multirow[t]{2}{*}{ OB014 } & G033 & 0.8 \\
\hline & G034 & 0.9 \\
\hline
\end{tabular}




\begin{tabular}{|l|l|l|}
\hline Kode Obat & Kode Gejala & Bobot \\
\hline & G035 & 0.7 \\
\cline { 2 - 3 } & G036 & 0.6 \\
\hline
\end{tabular}

\subsubsection{Data Aturan Bayes}

Tabel data aturan bayes dapat dilihat pada Tabel 5 .

Tabel 5. Tabel Aturan Bayes

\begin{tabular}{|c|c|c|}
\hline No & Nilai Bayes & Keterangan \\
\hline 1 & $0.0-0.2$ & Tidak Ada \\
\hline 2 & $0.3-0.4$ & Mungkin \\
\hline 3 & $0.5-0.6$ & Kemungkinan \\
\hline
\end{tabular}

\begin{tabular}{|c|c|c|}
\hline No & Nilai Bayes & Keterangan \\
\hline 4 & $0.7-0.8$ & Hampir Pasti \\
\hline 5 & $0.9-1$ & Pasti \\
\hline
\end{tabular}

\section{ANALISIS DAN PEMBAHASAN}

Analisis sistem dilakukan dengan menyeleksi gejala pasien menggunakan data pemeriksaan pasien yang diperoleh dari klinik Pratama Aisyiah.

\subsection{Validasi Hasil}

Validasi antara hasil sistem dengan data rekam medis dapat dilihat pada Tabe

Tabel 6. Validasi Hasil

\begin{tabular}{|c|c|c|c|c|c|c|}
\hline \multirow{2}{*}{ No } & \multirow{2}{*}{$\begin{array}{c}\text { No } \\
\text { RM } \\
\end{array}$} & \multirow{2}{*}{ Nama } & \multicolumn{2}{|c|}{ Hasil dari Sistem } & \multirow{2}{*}{ Hasil RM } & \multirow{2}{*}{ Validasi } \\
\hline & & & Nilai & Obat & & \\
\hline 1 & 12585 & Ponijo & 0.99 & Paracetamol & Paracetamol & Sesuai \\
\hline 2 & 10331 & Teguh R. & 0.99 & Paracetamol & Paracetamol & Sesuai \\
\hline 3 & 6555 & Surajiman & 0.55 & Antasida & Antasida & Sesuai \\
\hline 4 & 12062 & Faisal R. & 0.91 & Alpara & Alpara & Sesuai \\
\hline 5 & 12589 & Asep SN & 0.81 & Povidone Iodine & Amoxilin & Tidak Sesuai \\
\hline 6 & 6100 & Syifa NA & 0.99 & Paracetamol & Paracetamol & Sesuai \\
\hline 7 & 13436 & Bambang P. & 0.63 & Gliserid Guaiakolat & Gliserid Guaiakolat & Sesuai \\
\hline 8 & 6022 & Nonna A. & 0.99 & Norit & Lacto B & Tidak Sesuai \\
\hline 9 & 12831 & Irfan F. & 0.97 & Alpara & Alpara & Sesuai \\
\hline 10 & 13051 & M. Alfian & 0.83 & Piramel Pamoat & Piramel Pamoat & Sesuai \\
\hline 11 & 11963 & Shinva D. & 0.99 & Paracetamol & Paracetamol & Sesuai \\
\hline 12 & 10618 & Daffa A. & 0.91 & Alpara & Alpara & Sesuai \\
\hline 13 & 13408 & Jakiman & 0.63 & Diphenhydramin HCI & Diphenhydramin HCI & Sesuai \\
\hline 14 & 7103 & Maulina & 0.58 & Miconazole & Miconazole & Sesuai \\
\hline 15 & 11547 & Ny. Isna & 0.91 & Alpara & Alpara & Sesuai \\
\hline 16 & 13556 & Moeti E. & 0.97 & Alpara & Alpara & Sesuai \\
\hline 17 & 12715 & Agung P. & 0.99 & Paracetamol & Paracetamol & Sesuai \\
\hline 18 & 11693 & M. Iqbal & 0.99 & Paracetamol & Paracetamol & Sesuai \\
\hline 19 & 8315 & Asyifa SB & 0.55 & Antasida & Antasida & Sesuai \\
\hline 20 & 13467 & Siti A. & 0.97 & Alpara & Alpara & Sesuai \\
\hline
\end{tabular}

\subsection{Pembahasan}

Pembahasan mengambil salah satu sampel data kasus, sepeti berikut:

Nama $=$ Ponijo, Kode Gejala $1=$ G009, Gejala

= Kepala, leher, dan tubuh terasa panas, sedang tangan dan kaki dingin, Kode Gejala $2=$ G010, Gejala $=$ Mungking merasa kedinginan bila suhu meningkat.

Keterangan:

1. Bobot gejala ke-1 dengan kode gejala $\mathrm{G} 009=0.8$

2. Bobot gejala ke-2 dengan kode gejala $\mathrm{G} 010=0.6$

\subsection{Proses Inferensi}

Proses inferensi merupakan proses perhitungan data yang terdapat pada Tabel 6, proses iferensi dalam penelitian ini berupa flowchart, dapat dilihat pada Gambar 2. 


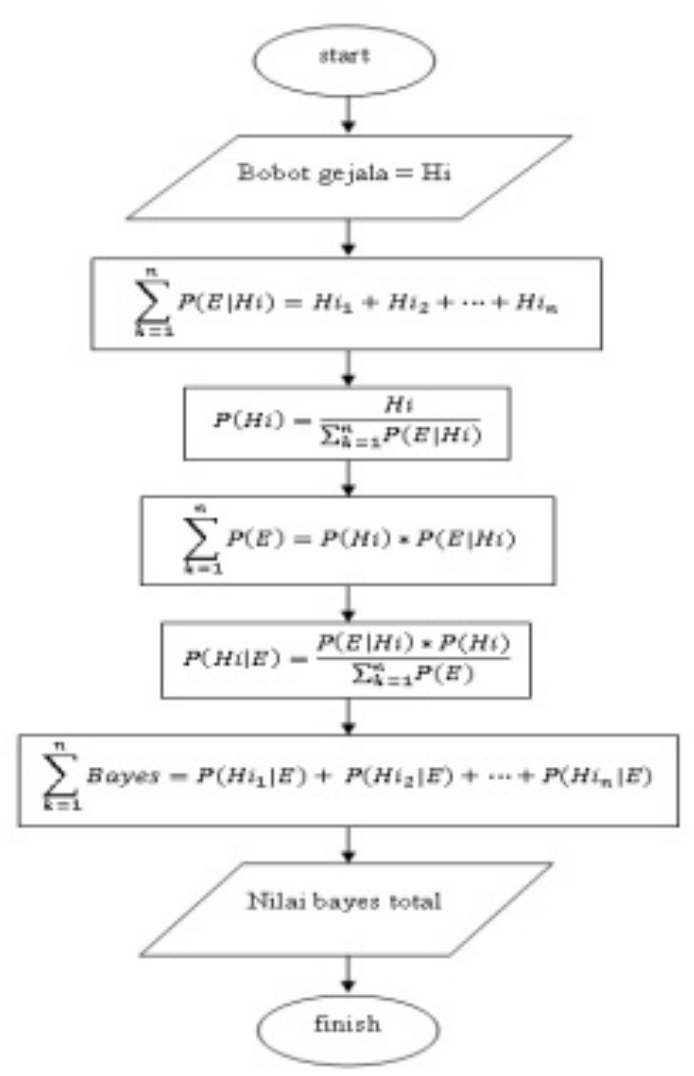

Gambar 2. Flowchart Proses Inferensi

Langkah proses inferensi seperti berikut:

1. Mencari Nilai Semesta.

Untuk mencari nilai semesta dinyatakan dalam Persamaan 2.

$$
\sum_{k=1}^{n} P(E \mid H i)=H i_{1}+H i_{2}+\cdots+H i_{n}(2)
$$

Diketahui bobot yaitu:

Bobot gejala ke- $1=0.8$

Bobot gejala ke- $2=0.9$

Nilai semesta $=0.8+0.9=1.7$

2. Menghitung Nilai Semesta

Untuk menghitung nilai semesta dinyatakan dalam Persamaan 3.

$$
\begin{aligned}
P(H i)=\frac{H i}{\sum_{k=1}^{n} P(E \mid H i)} \\
\mathrm{P}\left(\mathrm{Hi}_{1}\right)=\frac{0.8}{1.7}=0.47 \\
\mathrm{P}\left(\mathrm{Hi}_{2}\right)=\frac{0.9}{1.7}=0.53
\end{aligned}
$$

3. Menghitung Probabilitas H Tanpa Memandang Evidence Apapun

Dinyatakan dalam Persamaan 4.

$$
\sum_{k=1}^{n} P(E)=P(H i) * P(E \mid H i)
$$

$$
\begin{aligned}
& \mathrm{P}\left(\mathrm{Hi}_{1}\right) * \mathrm{P}\left(\mathrm{E} \mid \mathrm{Hi}_{1}\right)=0.47 * 0.8=0.38 \\
& \mathrm{P}\left(\mathrm{Hi}_{2}\right) * \mathrm{P}\left(\mathrm{E} \mid \mathrm{Hi}_{2}\right)=0.53 * 0.9=0.48 \\
& \text { Nilai total }=0.38+0.48=0.86
\end{aligned}
$$

4. Menghitung Nilai $\mathrm{P}(\mathrm{Hi} \mid \mathrm{E})$

Untuk menghitung nilai $\mathrm{P}(\mathrm{Hi} \mid \mathrm{E})$ dinyatakan dalam Persamaan 5.

$$
\begin{array}{r}
P(H i \mid E)=\frac{P(E \mid H i) * P(H i)}{\sum_{k=1}^{n} P(E)} \\
\mathrm{P}\left(\mathrm{Hi}_{1} \mid \mathrm{E}\right)=\frac{0.8 * 0.47}{0.86}=0.44 \\
\mathrm{P}\left(\mathrm{Hi}_{2} \mid \mathrm{E}\right)=\frac{0.9 * 0.53}{0.86}=0.55
\end{array}
$$

5. Menghitung Nilai Bayes

Untuk menghitung nilai bayes dinyatakan dalam Persamaan 6.

$$
\begin{aligned}
\sum_{k=1}^{n} \text { Bayes }= & P\left(H i_{1} \mid E\right)+P\left(H i_{2} \mid E\right)+\cdots+ \\
& P\left(H i_{n} \mid E\right)(6)
\end{aligned}
$$

Proses mencari nilai bayes yaitu:

Nilai bayes $=0.44+0.55=0.99$

Dari hasil perhitungan di atas yang mengacu pada sampel data pada Tabel 6 di dapatkan obat untuk terapi atas gejala yang dialami yaitu obat "Paracetamol", selanjutnya dicocokan dengan data aturan bayes bahwa nilai 0.9 - 1 adalah "Pasti". Maka obat yang dianjurkan untuk terapi atas gejala yang dialami pasien atas nama Ponijo yaitu "Paracetamol".

\section{KESIMPULAN DAN SARAN}

\subsection{Kesimpulan}

Dari penelitian yang telah dilakukan, dengan mengambil 20 data rekam medis dari klinik Pratama Aisyiyah, Sewugalur Kulon Progo yang telah divalidasi oleh Arif Yusuf Wicaksana, M.Sc., Apt., dan telah diuji menggunakan sistem, kesimpulan yang diperoleh adalah sebagai berikut:

1. Tingkat kesesuaian sistem menggunakan metode teorema bayes pada pemilihan obat secara swamedikasi yang telah diuji adalah sebesar $90 \%$.

2. Hasil keluaran pada sistem hanya dapat menampilkan informasi 1 jenis obat saja.

\subsection{Saran}

Dalam penelitian ini penulis menyadari masih banyak kekurangan, untuk itu sangat diperlukan adanya pengembangan terhadap 
sistem pakar pemilihan obat secara swamedikasi menggunakan metode teorema bayes, saran-saran yang dapat diberikan untuk pengembangan lebih lanjut mengenai penelitan ini antara lain:

1. Perancangan aplikasi sistem pakar dapat menganalisa tentang obat-obatan lain untuk proses penentuan terapi obat, misalnya menggunakan obat-obatan herbal alami.

2. Sistem pakar ini dapat dikembangkan menjadi aplikasi berbasis mobile.

\section{DAFTAR PUSTAKA}

Arhami, M. (2005). Konsep Dasar Sistem Pakar. Yogyakarta: Andi.

Barus, V. M., Mesran, Suginam, \& Karim, A. (2017). Sistem Pakar Untuk Mendiagnosis Hama Pada Tanaman Jambu Biji Menggunakan Metode Bayes. Jurnal INFOTEK, 78-81.

CMPMedica Asia Pte Ltd. (2009/2010). MIMS Petunjuk Konsultasi. Jakarta: PT Bhuana Ilmu Populer (Kelompok Gramedia).

Departemen Kesehatan RI. (2006). Pedoman Penggunaan Obat Bebas Dan Bebas Terbatas. Jakarta: Departemen Kesehatan RI.

Fahlefiana, N. (2013). Perancangan Aplikasi Sistem Pakar Dalam Penentuan Jenis Obat Kimiawi Sintesis Untuk Penyakit Pencernaan Dengan Metode Certainty Factor. Pelita Informatika Budi Darma, 93-96.

Harijanto, B., \& Latif, R. A. (2016). Sistem Pakar Diagnosa Penyakit Pada Kucing Dengan Metode Teorema Bayes Berbasis Android. Jurnal Informatika Polinema, 176-180.

Nurhayati, Kusumadewi, S., \& Miladiyah, I. (2016). Sistem Pakar Pemilihan Obat Antihipertensi Dan Interaksi Obat Atau Makanan. Jurnal Ilmiah Rekam Medis dan Informatika Kesehatan, 64-70.

Rikomah, S. E. (2016). Farmasi Klinik. Yogyakarta: Deepublish.

Rosnelly, R. (2012). Sistem Pakar Konsep Dan Teori. Yogyakarta: Andi.

Sidauruk, A., \& Pujianto, A. (2017). Sistem Pakar Diagnosa Penyakit Tanaman Kelapa Sawit Menggunakan Teorema Bayes. Jurnal Ilmiah DASI, 51-56.

Tan, H. T., \& Rahardja, K. (2010). Obat-Obat Sederhana Untuk Gangguan Seharihari. Jakarta: Elex Media Komputindo.
Turban, E. (1995). Decision Support And Expert Systems : Management Support Systems. New Jersey: Prentice Hall. 
8 Jurnal Multimedia \& Artificial Intelligence, Volume 1, Nomor 2, Agustus 2017 